Pain Physician. 2004;7:451-458, ISSN 1533-3159

\title{
THORACIC DISCOGRAPHY
}

\begin{abstract}
Vijay Singh, MD
Thoracic discography is performed much less frequently than either cervical or lumbar discography due to the relative infrequency of symptomatic thoracic disc pathology. Clinicians are less likely to ascribe thoracic pain to discogenic disease of the thoracic spine than to other more common etiologies, such as facet joint pain, muscle pain, skeletal pain or visceral pain. A comprehensive evaluation for pain includes hav-

ing an index of suspicion that includes the thoracic disc as the cause of these symptoms. The purpose of thoracic discography is to identify or confirm a thoracic disc as a pain generator.

The procedure itself has many similarities to the one used in the lumbar region; there are also similarities with the lumbar procedure with respect to patient selection and indications. Unintentional or inadver-

tent pleural puncture is a major risk of this procedure. It is a safe procedure when performed by an expert. Thoracic discography identifies the particular painful disc and provides a more complete description of thoracic disc pathology, correlated with MRI or CT findings.

Keywords: Discography, thoracic discography, thoracic disc herniation, thoracic pain, discitis
\end{abstract}

The technique that developed into discography was first described by Lindblom (1) when he used the term diagnostic disc puncture. Hirsch (2) used the procedure to identify painful discs in patients with sciatica and lumbar pain. Lindblom (1) did further work using the injection of contrast media to visualize radial tears in the annulus, expanding the diagnostic information from intervertebral discs. Pain provocation upon injection served to localize the painful disc and radiographic appearance with contrast gave information about the internal morphology of the disc.

Cloward and Busade (3) described the technique, use and indications for discography in both the lumbar and cervical regions over fifty years ago and the clinical use of discography has expanded enormously in the years since. Lumbar discography and, to a somewhat lesser extent cervical discography, has been extensively documented, practiced and refined

From Pain Diagnostics Associates, Niagara, Wisconsin.

Address Correspondence: Vijay Singh MD, Medical Director, Pain Diagnostics Associates, 1601 Roosevelt Rd, Niagara WI 54151

Disclaimer: Nothing of monetary value was received in the preparation of this manuscript.

Conflict of Interest: None

Acknowledgement:

Manuscript received on 06/06/04

Revision submitted on $08 / 10 / 04$

Accepted for publication on 09/10/04 over the past five decades. Thoracic discography has been used as a safe procedure by skilled interventionalists, and its main purpose is to precisely identify and localize the disc level producing primary symptoms.

Degeneration of the thoracic disc, along with end-plate irregularities and changes due to osteophyte formation, is largely confined to the mid-thoracic region. The contribution of other structures in chronic thoracic spinal pain has received little attention (5). Only a limited number of publications have discussed thoracic facet joints as sources of thoracic spinal pain. Manchikanti et al (6) noted that thoracic spinal pain, while being less common, has been reported as disabling as low back pain, and that the role of facet (zygapophysial) joints has been implicated in $48 \%$ of patients with chronic thoracic spinal pain without clinical or radiologic evidence of disc involvement.

Another enigma of thoracic disc pathology is a pain pattern mimicking visceral pain in the absence of true visceral pathology. Musculoskeletal pathology of the thoracolumbar junction can be mistaken for a gynecological problem with pain referred to the pelvic region. Similarly disc pathology in the mid-thoracic region can present as chronic abdominal pain. The pain from lower thoracic area can be confused with renal or ureteral pain $(7,8)$.
Hence, in the absence of visceral pathology, pain due to disc pathology should be considered and thoracic discography becomes an important tool in the diagnostic work-up.

\section{Epidemiology of Thoracic Spinal Pain}

Epidemiological data for thoracic spinal pain relative to lumbar spinal pain are limited. In the literature, the preponderance of publications deal with degenerative changes of the spine in the lumbar area. In general, thoracic spinal pain is not as well studied for several reasons. It is not a common primary finding; the thoracic spine is a stable structure with decreased spinal pathology. Referred thoracic spinal pain is often confused with other visceral pain.

From the review of literature conducted by Lawrence (9) using radiological criteria mid-thoracic discs showed the greatest degree of changes associated with disc degeneration. Mechanically midthoracic discs are subject to greater axial compression and bending due to their location in the apex of the thoracic kyphotic curve of the adult (10). This finding is also supported by the phenomenon of disc calcification, seen as a response to mechanical loading stress, most often reported in discs in the mid-thoracic spine.

Linton et al (11) reported a prevalence of spinal pain in $66 \%$ of the population. The proportion of these patients re- 
Table 1. Indications for thoracic discography

1). Presence of persistent thoracic spinal pain, for whom traditional diagnostic
modalities have failed to identify the source of pain;

2). Traditional methods have identified disc abnormalities but discography is required to make the determination if they are responsible for the pain; pain being a physiologic phenomenon.

3). Spinal fusion is planned, and discography used to identify the levels to be fused;

4). Presence of post-fusion pain, to identify a site of pain

5). Presence of recurrent disc herniation that cannot be differentiated from scar tissue using traditional imaging methods.

porting thoracic spinal pain was $15 \%$. Occhipinti (12) found a $5 \%$ incidence in a survey of factory workers that lacked association with age. Anderson (13) found a prevalence of thoracic spinal pain in bus drivers to be $28 \%$. Arce and Dohrmann (14) reported that herniated thoracic discs made up 0.25 to $0.75 \%$ of all disc ruptures. These were found in the third to fifth decade of life, with a peak occurrence in the fourth decade. The male: female ratio was 1.5: 1.0. In their study they reviewed 280 cases and found an incidence of $75 \%$ of these herniations below $\mathrm{T} 8$, with a peak incidence of $28 \%$ at T11-12.

Singer et al (10) in a review of published surveys found a reported incidence of complaints attributable to the thoracic region to be $2 \%-26 \%$ with a prevalence range of $5 \%-34 \%$. It is possible that the true incidence of thoracic pain caused by any particular structure is unknown, given the range of values seen from these studies.

\section{Anatomic Considerations}

Thoracic discs share many characteristics of lumbar discs, with some unique features. Thoracic intervertebral discs have a well-defined nucleus pulposus, smaller in volumetric dimension than the lumbar disc nucleus, more centrally located, surrounded by a dense fibroelastic aggregation of collagen fibers comprising the outer portion of the disc, the annulus fibrosus. The normal thoracic nucleus pulposus will accept injection volumes of $0.5 \mathrm{~mL}$ to $0.6 \mathrm{~mL}$ without causing pain (4).

Thoracic intervertebral discs make up approximately one-sixth of the height of the thoracic spinal column, having a lesser proportionate vertical dimension in comparison to their cervical and lumbar counterparts. They are thinner anteriorly and thicker posteriorly, exhibiting an anterior wedge shape, a trend most pro- nounced in the mid thoracic region. This is in part responsible for the normal kyphotic curvature in the thoracic spine. Disc height dimensions are least in the superior thoracic regions, which may be a reason behind relative stiffness of those segments, as a greater disc height tends to decrease disc stiffness while a greater cross sectional area tends to increase it. Inferior segments, which are not constrained by the thoracic rib cage, show a gradual increase in range of motion. In the thorac-

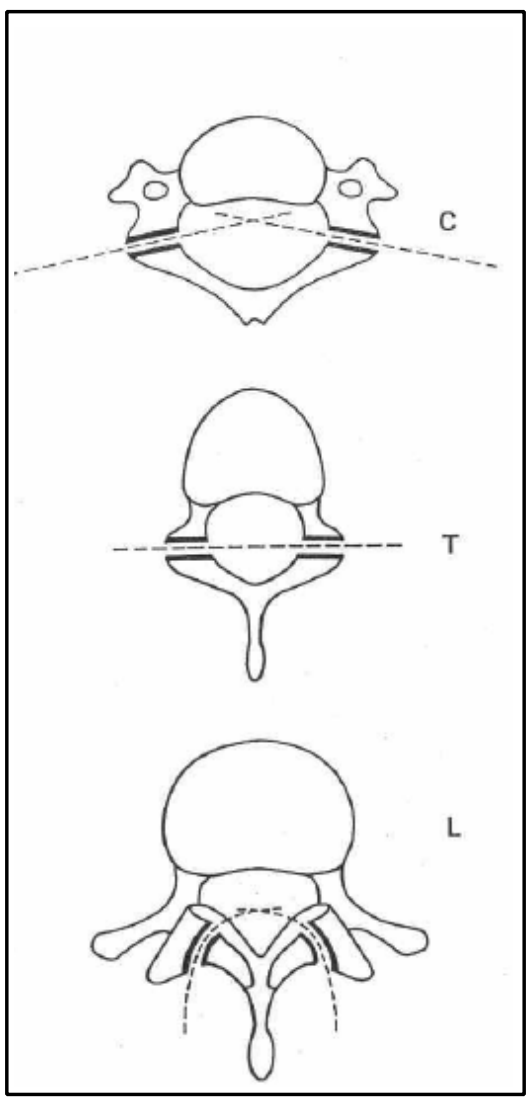

Fig 1. Orientation of facet joints, cervical, thoracic and lumbar regions, seen from transverse plane. ic spine, decreased vertical dimension of discs is in keeping with their functional role for axial loading and support.

The shape of thoracic discs varies from elliptical in the superior thoracic spine to what might be noted as a rounded triangle in the mid thoracic region, to a larger ellipse flattened posteriorly in the lower thoracic spine. Discs in the mid thorax show a more circular horizontal cross section than any other discs in the spine.

There is a linear increase in cross section area per Pooni et al (15) from the superior to the inferior thoracic region, increasing the degree of stiffness of the discs. Fibers of the annulus fibrosus are contiguous with Sharpey's fibers attaching to the vertebral end plates with the outermost fibers extending beyond the end plate into the periosteum of the vertebral body itself. There is great strength in this series of attachments between vertebral bodies with resistance to torsion being the outcome. The architecture of the thoracic spine is for axial loading and support with rela-

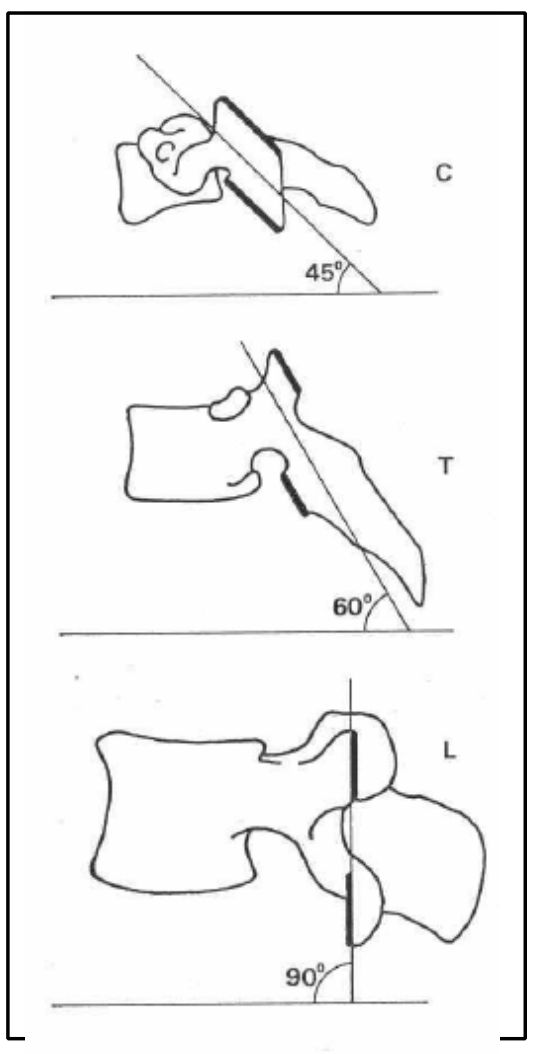

Fig 2.Orientation of the facet joints, cervical thoracic and lumbar, seen in Sagittal plane. Axial rotation in thoracic spine is restricted by facet joint orientation 


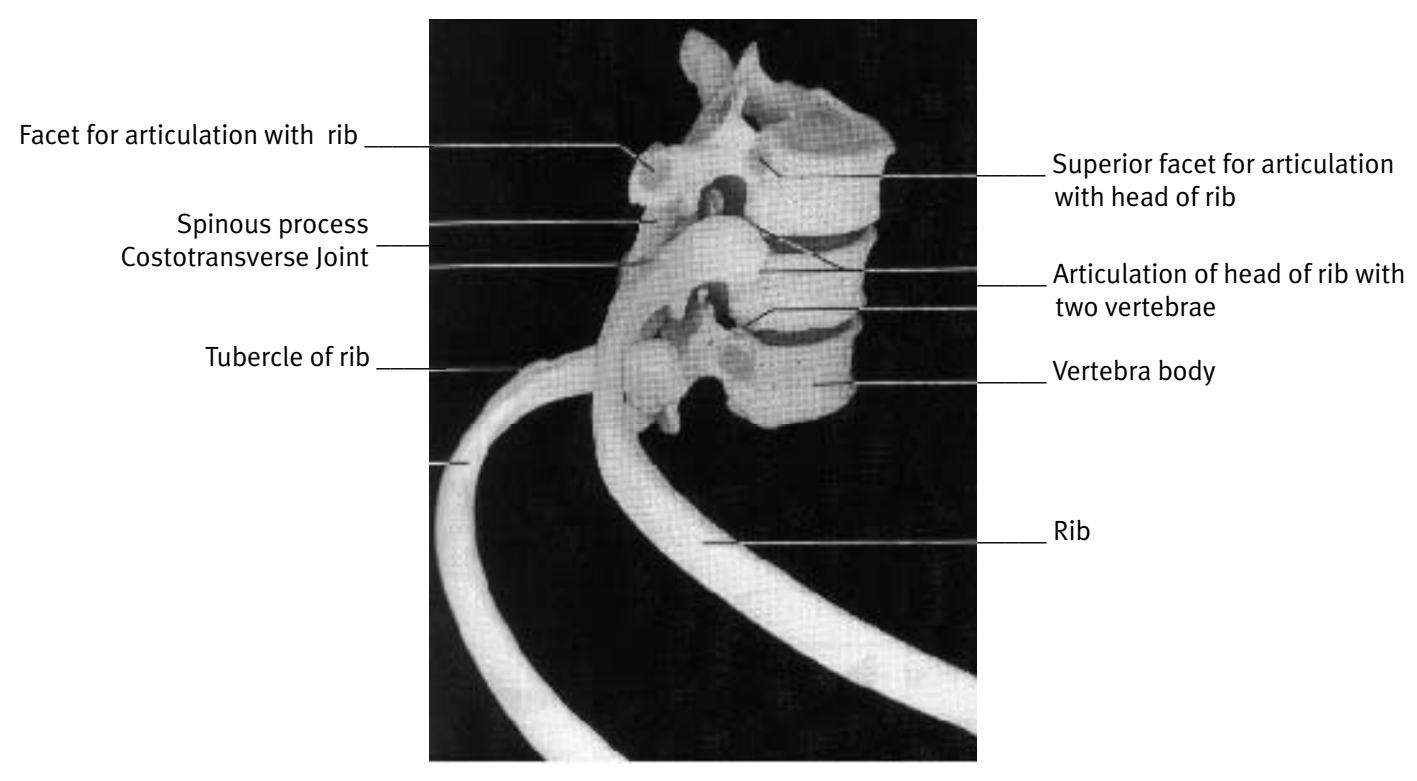

Fig 3. Bony structures in mid-thoracic segment

tively limited mobility. The thoracic spine disc permits vertebral mobility, while the facet joints provide restraint for rotational motion of the thoracic spine. This restriction of movement is shown by the orientation of facet joints.

Facet joint orientation varies with different levels of the spine. In the cervical spine, the superior articular processes face posteriorly and slightly laterally. In the thoracic spine, the processes face poste-

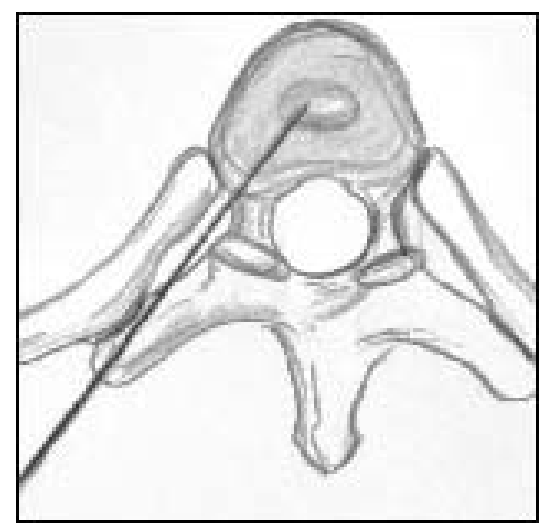

Fig 4. Needle placement for thoracic discography. Position for needle advancement is medial to the costotransverse junction along the lateral aspect of the superior articulating process. riorly while in the lumbar spine they face medially. The angles of inclination to the horizontal of the different levels of facet joints are as follows: 45 degrees for the cervical spine, 60 degrees for the thoracic and 90 degrees for the lumbar spine. The freedom of movement at each vertebral level is largely governed by the orientation of the facet joints (16) (Figs. 1 and 2).

This variable plane defined by facet joint position necessitates different imaging angulation to show the entrance to the disc space without obstruction by the adjacent vertebral body margins (Figs. 3 and 4). Accurate needle placement in thoracic discography requires different needle angulation and hence more skill by the interventionalist for a safe procedure.

\section{INDICATIONS FOR THORACIC DISCOGRAPHY}

MRI is useful in screening patients or as an initial examination for detection of disc disease. Many pathological changes are shown in MRI examination but the full characterization and confirmation of some disc pathology and pain-generating pathology may require the use of discography. MRI has other limitations when it comes to the identification of radial tears in the annulus. Three distinct types of annular tears have been characterized, circumferential tears, radial tears and transverse tears. Although MRI has been found to be an accurate means of identifying transverse and circumferential tears, it is less sensitive than discography in the identification of radial tears (17).

Osti and Fraser (18) also have noted that discography is more accurate than MRI for the detection of annular pathology; that a normal MRI does not exclude significant changes in the peripheral portion of the intervertebral disc.

A similar finding had been reported by Zucherman et al (19). They found that discograms might detect clinically significant pathology, usually annular disruptions, not suggested by normal MRI examinations. There are many other similar reports contrasting MRI and the essential role of discography, which is the identification of the exact disc causing pain.

Colhoun et al (20) performed a prospective study to define the role of lumbar discography in patients with low back pain with or without nondermatomal pain in the lower limb. In patients where discography had revealed disc disease and provoked symptoms, $89 \%$ derived significant and sustained benefit from surgical operation. Of those patients whose discs showed a morphological abnormality but did not have a provocation of symptoms with discography only $52 \%$ had clinical success. Successful outcomes were associated with positive discographic responses. 
Derby et al (21) conducted a study to further categorize positive discography findings, using a pressure and pain provocation classification system. The measurement of pressure-controlled diagnostic discography or discometry made it possible to quantify incremental injectate pressure accurately and measure the pressure at which pain was first elicited. The degree of disc sensitivity could be classified and recorded by determining pressures that correlate with disc pathology. Discs found to have a low threshold, namely those showing a positive pain response with lowest pressures, were identified as the most sensitive discs or 'chemically' sensitive discs.

Derby et al (21) state that identification of 'chemically' sensitive discs by manometric discography predicts those discs that will likely have a more favorable long-term follow up after surgical fusion. In his study, the subgroup of patients with the 'chemically' sensitive discs had better surgical outcomes than those patients with surgery who did not have chemically sensitive discs by discometry, and those without surgery fared the worst of all.

While ample intradiscal pressure data exist to characterize lumbar discs, there is a paucity of intradiscal thoracic pressure data. Recent work by Polga et al (23) examined in vivo pressures in healthy thoracic discs to determine the effect of both body position and physical maneuvers on intradiscal pressure in the middle and lower thoracic spine, and investigated possible variations of pressures with direction of measurement within the disc. They concluded that thoracic intradiscal pressures were significantly influenced by body position but not disc level.

Further work is needed with respect to thoracic discometry to determine if measurement of intradiscal thoracic disc pressures is as relevant as lumbar pressure data.

Intrinsic pressure measurements in lumbar discs were reported inversely related to disc degeneration in a cadaveric study by Panjabi (24) before lumbar discometry was advanced by Derby and further clinical usefulness of thoracic discometry may follow with this initial report.

Other authors like Moore et al (22) noted that patients who fail conservative therapy often fail to have good surgical outcomes as well and continue to have back pain. They advocate an aggressive surgical approach with fusion levels determined by MRI and discography and a solid arthrodesis (anterior and posterior) giving a high success rate.

\section{Contraindications}

It is imperative to study and review MRI examinations of the levels proposed for discography. There are very few absolute contraindications for the procedure. Cord compression, signs of active infection, the presence of neurological deficits and patient refusal for the procedure would be considered in this category.

Relative contraindications are coagulopathies and spinal stenosis at the level of the intended procedure.

\section{INTERPRETATION}

As in lumbar and cervical discography, obtaining a positive pain response from a known abnormal disc is a goal of the procedure. Provocative discography is called positive if the intradiscal injection causes pain and the patient recognizes it as the same pain leading to medical consultation. This pain is called concordant pain and grading on a sliding scale of $0-10$ ( 0 being absent pain and 10 being the worst pain imaginable by the patient) is usually done. The disc producing this pain is identified as the disc causing symptoms. During discographic discometry, manometric pressure can provide information regarding the intradiscal pressure when the pain first appears.

Pain provoked from the injection but recognized as different by the patient from the clinical complaint is known as discordant pain. Any equivocal response such as discordant pain may be one indication of a future problem or that the explanation for pain lies elsewhere and not in the disc being examined, with appropriate consideration for evaluation as needed.

Provocation of discordant pain in thoracic discography may be due to contrast filling an intraosseous herniation into the vertebral body known as Schmorl's node. They are often asymptomatic and not discovered until imaging studies are done. Several $(25,26)$ have suggested that Schmorl's nodes are found most often in areas of end-plate weakness, possibly from an incomplete embryonic notochord resorption. Regardless of the pathology leading up to extrusion of nuclear material into the vertebral body it is a herniation and may be painful with discography. Disc morphology revealed by the spread of contrast should be recorded, especially annular tears, fissures and leakage of contrast. Loss of disc height should be noted.

\section{Complications}

Unlike cervical or lumbar discography, thoracic discography remains more challenging from a technical point of view. The presence of the head of a rib and the attachment to the transverse process, the narrow disc space and the proximity of the pleura poses difficulty in the visualization and the accessing of the disc space. The disc space narrowing may be severe enough to preclude the safe performance of the procedure.

The complications that can arise in the performance of this procedure are less likely when strict attention to detail is followed. Judgment, experience and skill of the operator dictate continuation of the procedure in these instances. A complete, detailed rendition of the procedural technique is outside the scope of this discussion.

Pneumothorax has been mentioned as a possible severe complication. By using meticulous technique and carefully directed needle advancement this can be avoided. Immediate recognition of pneumothorax is essential, as this may not develop until the patient is in recovery. The same applies to damaging any thoracic cavity structure (Fig. 5).

Increased pain can result post-discography. Lehmer et al (27) described delayed-onset pain following discography and found it in patients with nearly normal disc morphology, which have incomplete or discrete annular tears that are not filled at the time of discographic injection. They maintained that contrast leakage occurs through these lesions at a later time, between 2 and 12 hours post-procedure causing the discogenic pain. Tallroth et al (28) also reported iatrogenic complications in their series of patients, with headaches in $10 \%$ attributed to leakage of contrast from the disc.

Any insult to annular integrity may raise concern of further damage compromising the disc. An animal study by Etheir et al (29) concluded that attempts should be made to minimize annular injury. This study compared annulotomy incision types and degrees of healing and while it did not directly address disc puncture by fine needle it may still be relevant for its remarks concerning disc in- 
jury. Johnson (30) addressed the question with repeat discograms an average of 16.7 months after initial discograms (range 3-38 months) and did not find any evidence that diagnostic discography damaged normal discs.

It is extremely rare but a delayed epidural abscess has been reported following discography (31).

The most watched-for complication in discography is discitis. Prophylaxis with appropriate antibiotics given at proper times before any procedure can insure that the antibiotic levels in the disc reach Minimal Inhibitory Concentrations (MICs) against the most common skin contaminants, Staphylococcus aureus and Staphylococcus epidermidis. Several antibiotics are suitable, including cefazolin, gentamycin, ceftriaxone and clindamycin (32). With several families of acceptable antibiotics, allergies and sensitivities should not be an issue. Some authorities favor the use of intradiscal antibiotics (33). Others, notably Schellhas (34), do not advocate the routine use of prophylactic antibiotics and instead emphasize speed and sterile technique in the procedure. Schellhas et al (34) reported complete absence of infectious complications with a fine needle technique in their series of over 8000 procedures.

Note should be made of a reported complication using cefazolin. Inadvertent or accidental introduction of cephalosporins to the intrathecal space may lead to the development of seizure activity, even if there is an absence of prior history (35).

\section{DISCUSSION}

In spite of the development and advancements in MRI in visualizing and identifying intervertebral disc degeneration and pathology, the exact origins of thoracic spinal pain are difficult to localize and determining the significance of a disc lesion and correlating it to a given clinical complaint is very inexact. The diagnosis of discogenic thoracic pain requires discography to reach an accurate decision for treatment planning.

Schellhas et al (34) described an anatomic basis of thoracic spinal pain origin. They noted the high degree of variability seen in the presentation of spinal pain, which often mimics visceral pathologic conditions, as well as causing muscle or back pain symptoms. They also presented a compilation of pain/pressure provocation findings, attempting to relate pain upon injection with anatomic location of tears around the disc circumference.

The hypotheses included anterior thoracic annular tears referring pain to anterior extra-spinal sites such as ribs, thorax and chest wall or visceral structures within the thorax or upper abdomen. Also, posterior annular tears with or without disc protrusion causing neural impingement were implicated producing back pain, locally or diffusely. Anoth- er observational hypothesis was that contained herniation, with internal disc derangement characterized by full thickness annular tears without herniation might also be concordantly painful and clinically significant.

The work by Wood et al (4), focused instead on their finding that MRI missed painless disc pathology identifiable with discography. Normal discs in the thoracic spine were relatively rare and were not painful upon injection. They also note that half of the discs in the symptomatic back pain group were concordantly painful upon injection. They concluded that this may have implications for multiple levels of pathology in symptomatic individuals and should be a matter of concern when surgical approaches are considered. Consequently, Wood et al (4) felt that this establishes thoracic discography as an important tool in the investigation of individuals with thoracic spinal pain, especially when surgery is contemplated. Again as in Walsh's study (36), many discs that were read as morphologically normal on MRI were found on discography to have varying degrees of annular pathology. An example of thoracic discography revealing a three-level degeneration pattern which was reported as normal appearing by MRI examination is illustrated in Fig 6. Anterior leakage noted at T9-T10 during discography was a significant finding which correlated with the patient's symptoms. This finding was

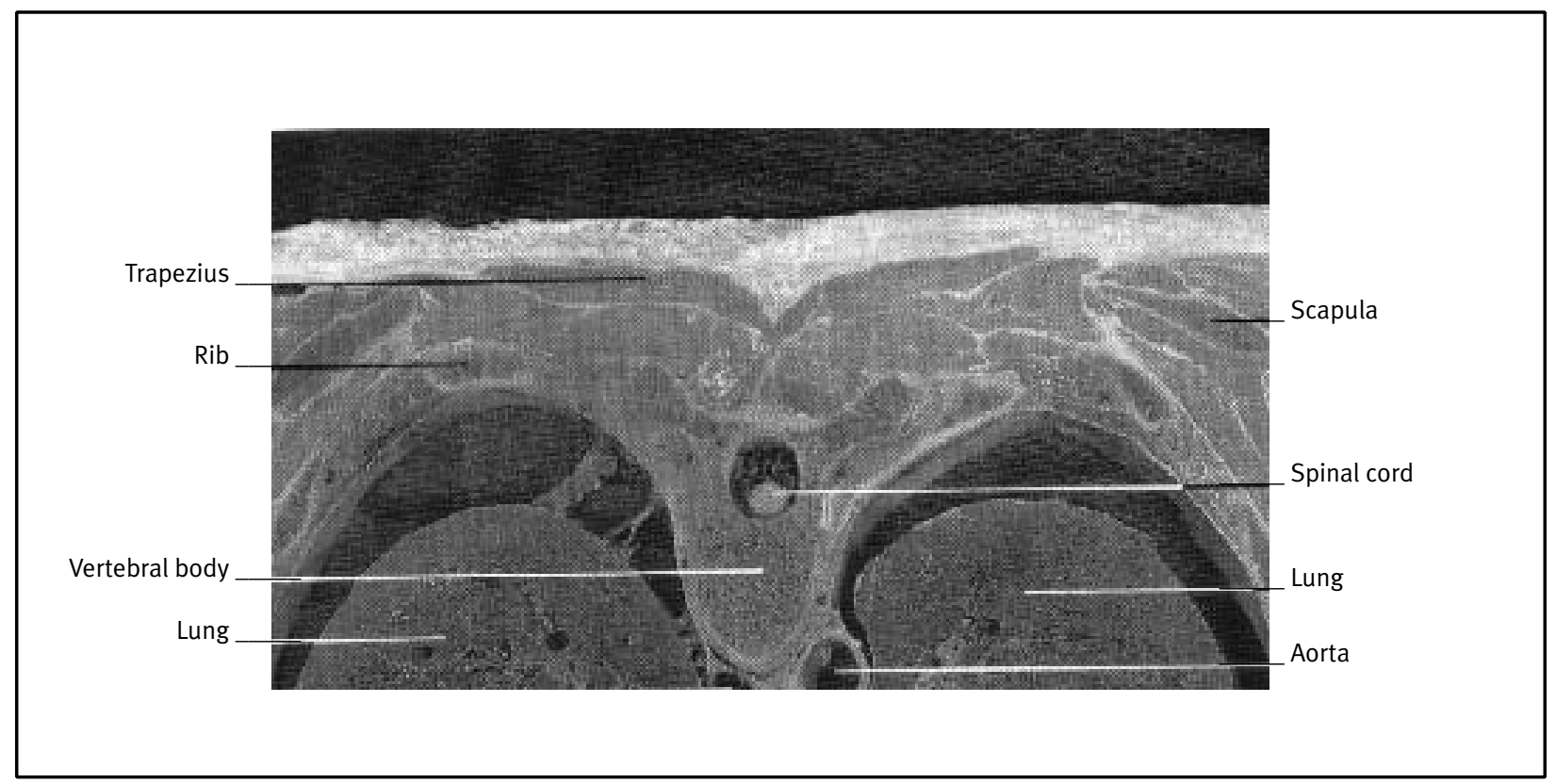

Fig 5. Important landmarks in cross-section of cadaver thoracic cavity. 


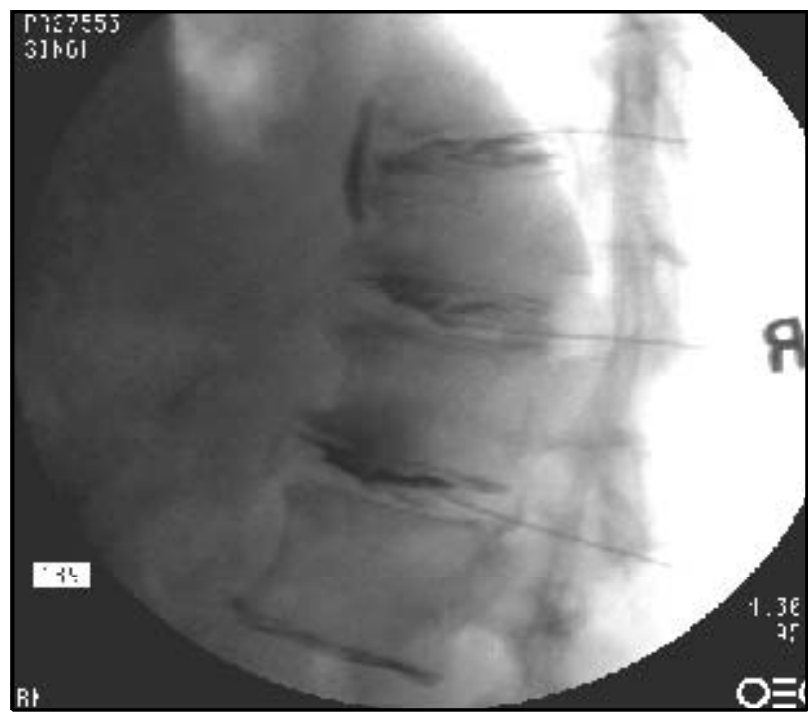

Fig 6. Lateral view thoracic discograms. T9/10, T10/11 and T11/12. Note contrast leaking anteriorly at T9/10. Severe degeneration at T10/11 and T11/12, with contrast highlighting posterior bulge at T11/12.

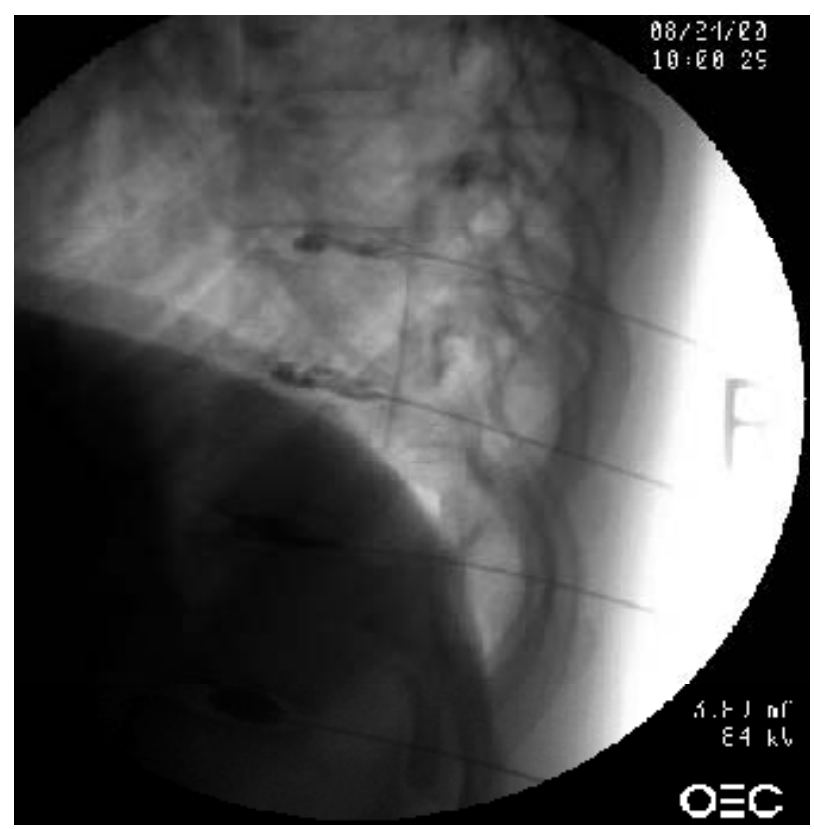

Fig 8. Lateral view of thoracic discogram in mid-thoracic region. Disc spaces are slightly narrower in this region, compared to Fig 7 .

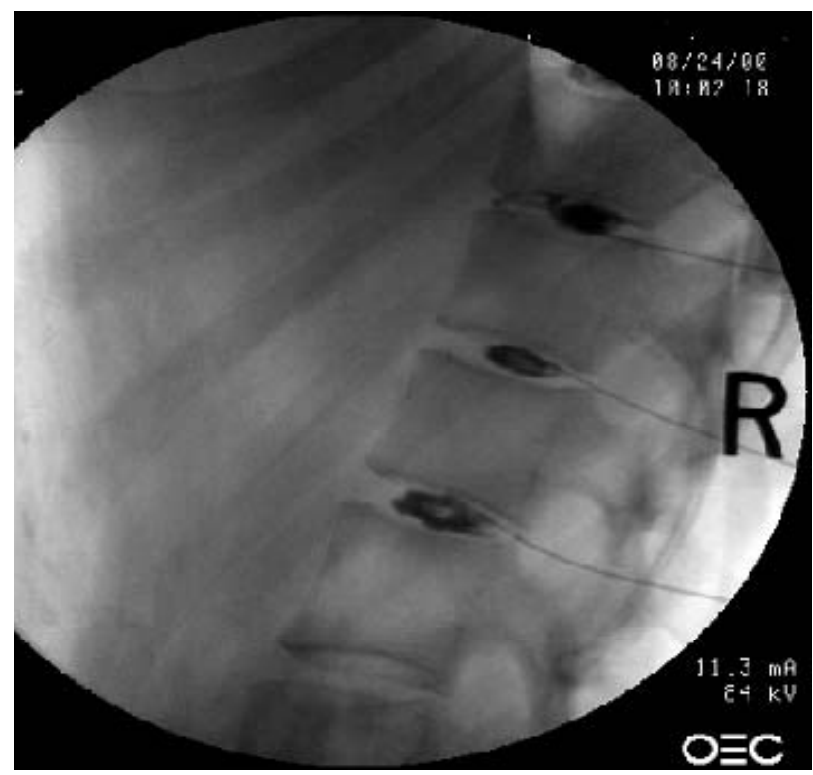

Fig 7. Example of wider disc spaces in the lower thoracic and upper lumbar spine. Contrast visible at four levels T10-T11, T11-T12, T12-L1 and L1-L2.

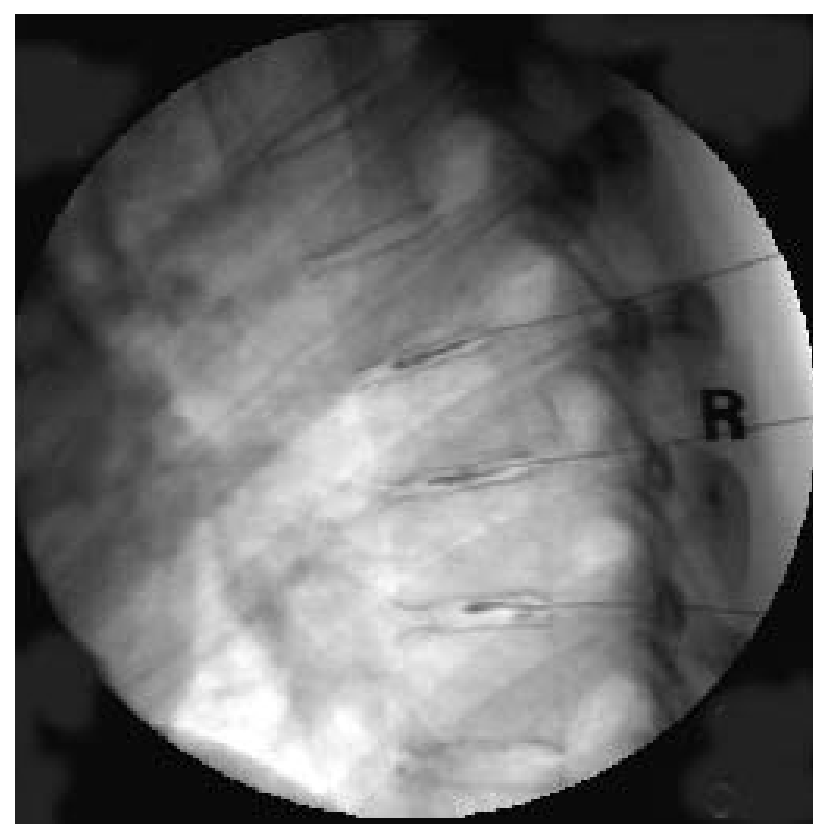

Fig 9. Lateral view thoracic discography. T6-T7, T7- T8 and T8-T9, showing quite narrow disc spaces at these levels compared to those shown in Fig 7 and 8. disclosed clearly during discography and could never have been detected if the examination had been limited to MRI.

Wood et al (4) also emphasized the necessity to know spinal canal dimensions in the thoracic region to avoid complications from cord compression. Both groups report similar patient selection criteria to greatly decrease risks from the procedure.
It is also important to know the dimensions of the disc spaces themselves. Narrowness of the disc space may pose many difficulties, and increase the risk of inadvertent puncture of structures in the thoracic cavity (Fig. 5). Disc spaces are relatively narrower in the upper thoracic region in comparison to the lower thoracic segments (Figs. 7 - 10).
Winter and Schellhas (37) described a case report that showed the full utility of both MRI and discography in a patient, with the former being used to show multilevel disc degeneration and the latter used to reveal concordantly painful thoracic discs levels prior to surgical correction of chronically painful adult Scheuermann's disease. 


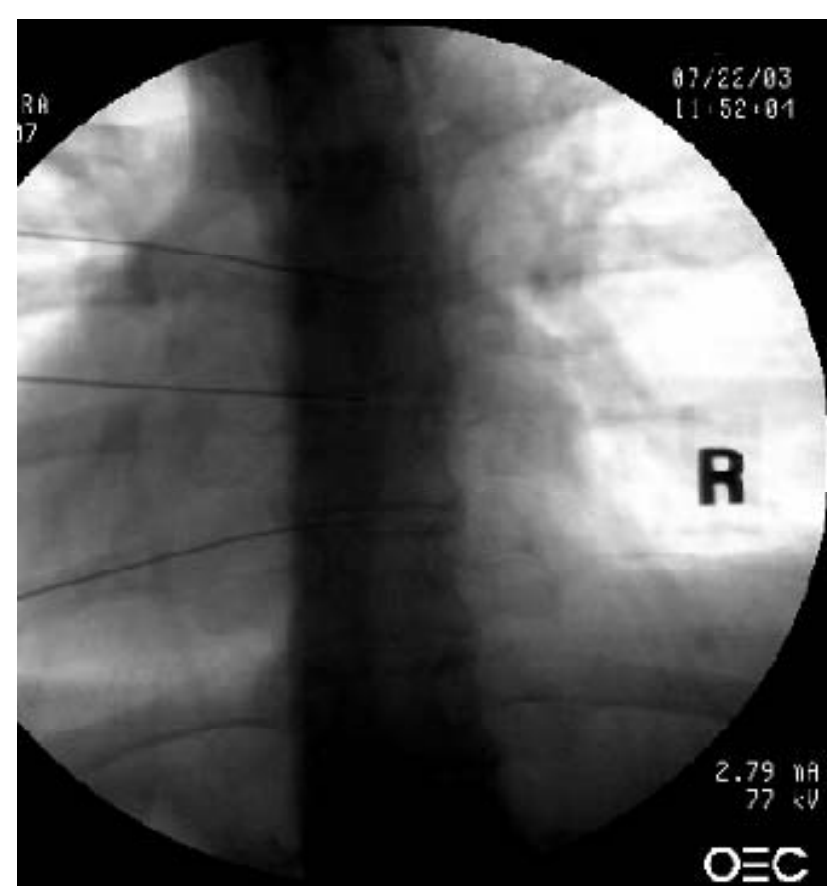

Fig 10. AP view of narrow disc spaces at T6-T7, T7-T8 and T8-T9

\section{ConCLusion}

Thoracic discography is indicated when conventional radiologic imaging does not disclose an etiology for thoracic pain. This is a clinical decision made with input from the spine interventionalist. Referred visceral pain and musculoskeletal pain complicate the diagnosis of thoracic pain, often mimicking thoracic spinal pain or obscuring its origin (38). These factors are rarely present with presentations of cervical or lumbar pain. Thoracic discs may not be as prone to degeneration or damage and thoracic spinal pain is reported less often than lumbar or cervical pain. The majority of thoracic disc herniations are asymptomatic. Thoracic discography may find pathological lesions previously unknown or asymptomatic that may develop into future clinical problems.

Like lumbar and cervical discography, thoracic discography is not a screening procedure but rather a confirmatory one, especially when conventional radiologic imaging has not described or disclosed pathology responsible for symptoms.

Discography has been found very useful prior to any major spinal surgical procedure such as spinal fusion. Its role cannot be overestimated prior to any per- cutaneous disc decompression procedure as well. When repeat spine surgical intervention is necessary, discography has been found to influence outcomes favorably (20).

Thoracic discography is a very useful and safe procedure in the hands of an experienced discographer.

\section{Author Affiliation \\ Vijay Singh, MD \\ Medical Director \\ Pain Diagnostics Associates \\ 1601 Roosevelt Rd \\ Niagara WI 54151 \\ E-mail: vs@netnet.net}

\section{REFERENCES}

1. Lindblom K. Diagnostic puncture of intervertebral discs in sciatica. Acta Orthop Scand 1948; 17:231-239.

2. Hirsch C. An attempt to diagnose level of disc lesion clinically by disc puncture. Acta Orthop Scand 1948; 18:132-140.

3. Cloward RB, Busade LL. Discography: Technique, indications and evaluation of the normal and abnormal intervertebral disc. AJR Am / Roentgenol 1952; 68:552564.

4. Wood KB, Schellhas, KP, Garvey TA et al. Thoracic discography in healthy individuals. A controlled prospective study of magnetic resonance imaging and discography in asymptomatic and symptomatic individuals. Spine 1999; 24:1548-1555.

5. Singer KP, Edmondston SJ. Introduction: The enigma of the thoracic spine . In: Giles GF, Singer KP (eds.) Clinical Anatomy and Management of Thoracic Spine Pain. Butterworth Heineman, Boston, 2000:3-15.

6. Manchikanti L, Singh V, Pampati $V$ et al. Evaluation of the prevalence of facet joint pain in chronic thoracic pain. Pain Physician 2002; 5:354-359.

7. Whitcomb DC, Martin SP, Schoen RE et al. Chronic abdominal pain caused by thoracic disc herniation. Am J Gastrenterol 1995; 90:835-837.

8. Akhaddar A, Gazzazz M, Kadiri B et al. Chronic lumbar pain considered to be "Nephritic colic" after seven years, due to a thoracic disc herniation at T10-11. Ann Urol 2003; 37:173-176.

9. Lawrence JS. Rheumatism in Populations. William Heineman Medical Books, London 1977.

10. Singer KP. Pathomechanics of the aging thoracic spine. In Advances in Chiropractic Lawrence, ed.) Mosby, St. Louis, 1997: 129-153.

11. Linton SJ, HellsingAL, Hallden K. A population based study of spinal pain among 35 to 45 year old individuals. Spine $1998 ; 23$ : 1457-1463.

12. Occhipiniti E, Colombini D, Grieco A. Study of distribution and characteristics of spinal disorders using a validated questionnaire in a group of male subjects exposed to occupational spinal risk factors. Spine 1993; 18:1150-1159.

13. Anderson R, Mecker WC, Wieick BE et al. A meta analysis of clinical trials of spinal manipulation. JMPT 1992; 15:181-194.

14. Arce CA, Dohrmann GJ. Herniated thoracic discs. Neurol Clin 1985; 3:383-392.

15. Pooni JS, Hukins DW, Harris PF et al. Comparison of the structure of human intervertebral discs in the cervical, thoracic and lumbar regions of the spine. Surg Radiol Anat 1986; 8:175-182.

16. Maigne R. Zygapophyseal joints in: Section 1, Anatomy. Diagnosis and Treatment of Pain of Vertebral Origin. William and Wilkins, Baltimore, 1996, pp.10.

17. Yu SW, Haughton VM, Sether LA et al. Comparison of MR and discography in detecting radial tears of the annulus: A post mortem study. AJNR Am / Neuroradiol 1989; 10:1077-1081.

18. Osti OL, Fraser RD. MRI and discography of annular tears and intervertebral disc degeneration. A prospective clinical comparison. JBJS Br 1992; 74:431-435.

19. Zucherman J, Derby R, Hsu K et al. Normal magnetic resonance imaging with abnormal discography. Spine 1988; 13:13551359.

20. Colhoun E, MncCall IW, Williams L et al. Provocation discography as a guide to planning operations on the spine. $J B J S B r$ 1988; 70:267-271. 
21. Derby R, Howard MW Grant JM et al. The ability of pressure-controlled discography to predict surgical and nonsurgical outcomes. Spine 1999; 24:364-371.

22. Moore KR, Pinto MR, Butler LM. Degenerative disc disease treated with combined anterior and posterior arthrodesis and posterior instrumentation. Spine 2002; 27:1680-1686.

23. Polga DJ, Beaubien BP, Kallemeier PM et al. Measurement of in vivo intradiscal pressure in healthy thoracic intervertebral discs. Spine 2004; 29:1320-1324.

24. Panjabi M, Brown M, Lindahl S et al. Intrinsic disc pressure as a measure of integrity of the lumbar spine. Spine 1988; 13:913917.

25. Hilton R, Ball J, Benn R. Vertebral endplate lesions (Schmorl's nodes) in the dorsolumbar spine. Ann Rheum Dis 1976: 35: 127-132.

26. Peng $B, W u$ W, Hou $S$ et al. The pathogenesis of Schmorl's nodes. JBJS Br 2003; 85: 879-882.
27. Lehmer SM, Dawson MH, O’Brien JP. Delayed pain response after discography. Eur Spine J 1994; 3:28-31.

28. Tallroth K, Soini J, Antti-Poika I et al. Premedication and short term complications in iohexol discography. Ann Chir Gynaecol 1991; 80:49-53.

29. Ethier DB, Cain JE, Yaszemski MJ et al. The influence of annulotomy selection on disc competence. A radiographic, biomechanical and histological analysis. Spine 1994; 19:2071-2076

30. Johnson RG. Does discography injure normal discs? An analysis of repeat discograms. Spine 1989; 14:424-426.

31. Junila J, Niinimaki T, Tervonen O. Epidural abscess after lumbar discography. A case report. Spine 1997; 22:2191-2193.

32. Klessig Ht, Showsh SA, Sekorski A. The use of intradiscal antibiotics for discog. raphy: an in vivo study of gentamycin, cefazolin, and clindamycin. Spine 2003; 28: 1735-1738.

33. Boscardin JB, Ringus JC, Feingold DJ. Hu- man intradiscal levels with cefazolin. Spine 1992; 17:S145-148.

34. Schellhas KP, Pollei SR, Dorwart RH. Thoracic discography. A safe and reliable technique. Spine 1994; 19:2103-2109.

35. Boswell MV, Wolfe JR. Intrathecal cefazolin-induced seizures following attempted discography. Pain Physician 2004; 7:103 106.

36. Walsh TR, Weinstein JN, Spratt KR et al. Lumbar discography in normal subjects. A controlled, prospective study. JBJS Am 1990; 72:1081-1088.

37. Winter RB, Schellhas KP. Painful adult thoracic Scheuermann's disease. Diagnosis by discography and treatment by combined arthrodesis. Am J Orthop 1996; 25: 783-786.

38. Rohde RS, Kang JD Thoracic disc herniation presenting with chronic nausea and abdominal pain. J Bone Joint Surg 2004; 86:379-381. 